\title{
Changes in the faecal bile acid profile in dogs fed dry food vs high content of beef: a pilot study
}

Kristin Marie Valand Herstad ${ }^{1 *}\left(\mathbb{D}\right.$, Helene Thorsen Rønning ${ }^{2}$, Anne Marie Bakke ${ }^{3}$, Lars Moe ${ }^{1}$ and Ellen Skancke

\begin{abstract}
Background: Dogs are fed various diets, which also include components of animal origin. In humans, a high-fat/ low-fibre diet is associated with higher faecal levels of bile acids, which can influence intestinal health. It is unknown how an animal-based diet high in fat and low in fibre influences the faecal bile acid levels and intestinal health in dogs. This study investigated the effects of high intake of minced beef on the faecal bile acid profile in healthy, adult, client-owned dogs $(n=8)$ in a 7-week trial. Dogs were initially adapted to the same commercial dry food. Thereafter, incremental substitution of the dry food by boiled minced beef over 3 weeks resulted in a diet in which $75 \%$ of each dog's total energy requirement was provided as minced beef during week 5. Dogs were subsequently reintroduced to the dry food for the last 2 weeks of the study. The total taurine and glycine-conjugated bile acids, the primary bile acids chenodeoxycholic acid and cholic acid, and the secondary bile acids lithocholic acid, deoxycholic acid (DCA) and ursodeoxycholic acid (UDCA) were analysed, using liquid chromatography-tandem mass spectrometry.

Results: The faecal quantities of DCA were significantly higher in dogs fed the high minced beef diet. These levels reversed when dogs were reintroduced to the dry food diet. The faecal levels of UDCA and taurine-conjugated bile acids had also increased in response to the beef diet, but this was only significant when compared to the last dry food period.
\end{abstract}

Conclusions: These results suggest that an animal-based diet with high-fat/low-fibre content can influence the faecal bile acids levels. The consequences of this for canine colonic health will require further investigation.

Keywords: Commercial dry food, Healthy client-owned dogs, Minced beef, Primary and secondary bile acids

\section{Background}

Bile acids (BA) are essential for digestion and absorption of dietary lipids and lipid-soluble vitamins in the small intestine in mammals as well as in other vertebrates [1]. Studies mainly performed in cell-lines from humans and laboratory animals describe that BA also function as signalling molecules by activating receptors in the gall bladder, intestine and accessory digestive organs. These receptors and their ligands are involved in the regulation of lipid and glucose homeostasis [2-4] and they are

\footnotetext{
*Correspondence: kristin.herstad@nmbu.no

${ }^{1}$ Department of Companion Animal Clinical Sciences, Faculty of Veterinary Medicine, Norwegian University of Life Sciences (NMBU), Oslo, Norway

Full list of author information is available at the end of the article
}

believed to modulate the immune response in the liver and intestine [5]. However, high levels of some of these BA are toxic for colonic cells [6-8], and their concentrations are therefore tightly regulated [9].

The primary BA, cholic acid (CA) and chenodeoxycholic acid (CDCA) are synthetized from cholesterol and conjugate with either glycine or taurine in the liver. The latter is the most common in dogs [10,11]. Most conjugated BA $(>95 \%)$ are reabsorbed in the ileum [12] and are returned to the liver through the enterohepatic circulation. BA that escape absorption, are deconjugated and converted through 7 alpha-dehydroxylation to secondary BA by colonic bacteria. The secondary BA deoxycholic acid (DCA) and lithocholic acid (LCA) originate from CA and CDCA, respectively [13]. Ursodeoxycholic acid 
(UDCA) is also produced by bacterial transformation from the primary BA CDCA [14].

Although dogs have adapted to a diet containing considerable amounts of carbohydrates through the domestication process, they were originally carnivores $[15$, 16]. In humans, a diet consisting of high content of animal derived protein and fat, and low content of carbohydrates, has been associated with increased faecal levels of BA, including DCA [8]. High levels of DCA may contribute to the formation and/or progression of colorectal tumours in humans [17] and mice [7, 18]. In contrast, UDCA is considered to have chemopreventative properties, and may counteract the effect of DCA, as demonstrated in human colon cancer cell lines [19, 20]. Colorectal tumours are rarely diagnosed in dogs $[21,22]$, yet they are considered more common in dogs than in other animal species [23]. Since similar molecular mechanisms have been described in the colorectal tumorigenesis in humans and dogs [24-26], and as dogs live in similar environments as humans, knowledge regarding how diet influences the faecal BA composition may be valuable for both dogs and humans.

Characterization of the pre- and postprandial serum concentrations of total BA aids in identifying impaired hepatic function and is useful in diagnosing portosystemic shunts (PSS) in dogs [27]. However, the various BA are rarely measured in faeces, and studies characterizing the canine faecal BA profile are sparse [28-30]. Furthermore, little is known about how a meat-based diet influences the levels of these BA.

The aim of this study was therefore to use liquid chromatography-tandem mass spectrometry (LC-MS/MS) to characterize the faecal BA profiles in healthy dogs before, during and after a diet with high content of boiled minced beef $(\mathrm{MB})$.

\section{Methods}

The study protocol was reviewed and approved according to the guidelines of the ethics committee at the Faculty of Veterinary Medicine and Biosciences, Norwegian University of Life Sciences (NMBU) (Approval Number: 14/04723-23). All dog-owners gave a written informed consent before participation and were informed that they could leave the study at any time.

\section{Animals, study design and diets}

The study population consisted of a heterogeneous population of healthy client owned dogs $(n=11)$ of both gender and of various breeds and ages. They were included in a 7-week prospective dietary intervention study (Table 1). Three dogs did not complete the study due to loose faeces/diarrhoea (faecal score $>4.5$, based on a fivepoint scale where grade 1 represents hard, dry faeces and
Table 1 Demographic overview of the eight client-owned dogs included in a 7-week dietary intervention study

\begin{tabular}{lllll}
\hline Dog no. $^{\text {a }}$ & Breed & $\begin{array}{l}\text { Gender } \\
\text { Female F/ } \\
\text { male M }\end{array}$ & $\begin{array}{l}\text { Age } \\
\text { (years) }\end{array}$ & $\begin{array}{l}\text { Body } \\
\text { weight } \\
\text { (kg) }\end{array}$ \\
\hline 1 & English Springer Spaniel & F & 8 & 19.5 \\
3 & Small Munsterlander & F & 6 & 21.5 \\
4 & Eurasier & F & 1.5 & 17.7 \\
5 & Irish Setter & M & 4 & 21.5 \\
6 & Mixed breed & M & 5 & 14.7 \\
7 & English Setter & M & 5 & 28 \\
10 & English Cocker Spaniel & F & 8 & 10.3 \\
11 & German Shorthaired & F & 3 & 19.9 \\
& Pointer & & &
\end{tabular}

a Dog no. 2, 8 and 9 did not complete all the diet periods

grade 5 represents watery diarrhoea) [31]. Thus, eight dogs completed all the diet periods and were included in the present investigation. A detailed description of the study, the dogs and the diets have been described previously [32]. In brief, all the dogs were adapted to a commercial dry food diet for 2 weeks (CD1). Thereafter, each dogs received a mixture of boiled minced beef (MB) and CD diet for 3 weeks, where the MB was gradually increased in weekly increments at the expense of the $\mathrm{CD}$ diet. Water was added to the minced beef at a ratio of 3 parts MB:1 part water and simmered for 15 min or until the meat was completely cooked. The meat with any remaining water was mixed with the $\mathrm{CD}$, cooled, and served. The amount of MB given each week was calculated to provide 25 (low minced beef, LMB), 50 (moderate minced beef, MMB) and 75 (high minced beef, $\mathrm{HMB}$ ) percent of the dog's total energy requirement. Finally, all the dogs were reintroduced to the original CD diet in the last 2 weeks of the study (CD2). The energy requirement for each adult dog was estimated according to information provided by the owner concerning type and amount of diet fed prior to the study and/or the range of 350-500 $\mathrm{kJ} \mathrm{ME} \times \mathrm{BW}^{0.75}$ based on activity level, coat quality, body weight and body condition score [33]. The energy content in diets were kept constant for each dog throughout the study period. The calculated content of macronutrients for these diets were as follows: CD: 27.1/100 g dry matter (DM) proteins, 16.3/100 g DM lipids, 48.3/100 g DM nitrogen-free extract (NFE; carbohydrate-containing fraction) and 10.4/100 g DM fibre (non-starch polysaccharides); and HMB: 46.2/100 g DM proteins, 33.1/100 g DM lipids, 15.6/100 g DM NFE, and 3.4/100 g DM fibre. The detailed composition of the diets are found in Additional file 1.

The data presented herein are from faecal samples collected and analysed from each of the dogs during the 
last 3 days from diet periods $\mathrm{CD} 1$ and $\mathrm{HMB}$, and from the last 2 days from diet period CD2. All faecal samples analysed had normal faecal consistency. Samples were freeze-dried (Christ Alpha 1-4; SciQuip, Shropshire, UK) [34] and subsequently frozen and stored at $-80{ }^{\circ} \mathrm{C}$ prior to further processing.

\section{Sample preparation}

Liquid chromatography-tandem mass spectrometry (LC-MS/MS) was used to analyse faecal BA. These included CA, CDCA, DCA, LCA, UDCA, and glycineand taurine conjugated forms of these BA. A detailed overview of the BA are found in Additional file 2. The method for extraction of BA was based on Hagio et al. [35] with the following modifications: A total of $100 \mu \mathrm{L}$ of $0.1 \mu \mathrm{g} / \mathrm{mL}$ internal standard was added to each freezedried faecal sample of $100 \mathrm{mg}$. Centrifugation of samples were performed at $4{ }^{\circ} \mathrm{C}$. The evaporation steps were performed at room temperature. The methanol extracts were purified with solid phase extraction using an Oasis HLB cartridge (Waters, Milford, MA, USA), following the generic Oasis HLB protocol. The eluates were evaporated to dryness at room temperature under a stream of air and the dry residues were reconstituted in $1 \mathrm{~mL}$ methanol/10 $\mathrm{mM}$ ammonium acetate $(1+1)$. The extracts were filtered through $0.22 \mu \mathrm{m}$ nylon spin filters (Spin-X, Costar, Corning Inc., Corning, NY, USA) for $3 \mathrm{~min}$ at $11,000 \times g$. The filtered extracts were transferred to $\mathrm{HPLC}$-vials and subsequently stored at $-20{ }^{\circ} \mathrm{C}$ until LC-MS/MS analysis.

\section{Liquid chromatography-tandem mass spectrometry (LC- MS/MS)}

The analysis was performed with an Agilent 1290 liquid chromatography system (Agilent Technologies, Waldbronn, Germany) coupled online with an Agilent G6490 triple quadrupole mass spectrometer (Agilent Technologies, Singapore) with a JetStream ESI ion source. The LC-MS/MS method described by Hagio et al. [35] was modified. The separation was done on a Waters Acquity BEH C18 column, $100 \mathrm{~mm} \times 2.1 \mathrm{~mm}$ i.d. and $1.7 \mu \mathrm{m}$ particles, with $10 \mathrm{mM}$ ammonium acetate in water as mobile phase A and acetonitrile as mobile phase B (MPB). The flow rate was $0.4 \mathrm{~mL} / \mathrm{min}$ and the column temperature $40{ }^{\circ} \mathrm{C}$. The gradient started with $1 \mathrm{~min} 20 \% \mathrm{MBP}$, then went from 20 to $50 \%$ MPB in 9 min, then from 50 to $95 \%$ MBP in $0.1 \mathrm{~min}$ followed by $3 \mathrm{~min}$ in $95 \% \mathrm{MBP}$. The column was equilibrated in $20 \%$ MPB for 3 min before the next injection. Total analysis time was $15 \mathrm{~min}$. The injection volume was $1 \mu \mathrm{L}$ and the auto sampler temperature $4{ }^{\circ} \mathrm{C}$.

All BA were ionized in negative mode and detected as their $(\mathrm{M}-\mathrm{H})-$ ions. The monitored ion transitions and compound specific parameters are given in Additional file 3a. All common MS/MS-parameters are provided in Additional file $3 \mathrm{~b}$.

Due to the ubiquitous presence of BA in faeces it was impossible to obtain a truly negative sample material. The method validation was therefore performed by spiking a pooled faecal sample with BA and subtracting the BA levels in the same sample without addition, to evaluate both linearity, precision and limit of detection. The precision study was done by spiking six samples at $100 \mu \mathrm{g} / \mathrm{g}$. The linearity was evaluated from spiked samples at five levels; $0.1,0.5,1,10$ and $50 \mu \mathrm{g} / \mathrm{g}$. Grade 1 water was used as negative control. The faecal BA concentrations were calculated relative to the spiked samples used to evaluate the precision. Therefore, this method is only semiquantitative. The faecal BA concentrations are expressed in $\mu \mathrm{g} / \mathrm{g} \mathrm{DM}$.

The precision at $100 \mu \mathrm{g} / \mathrm{g}$ was $<13 \%$ for all compounds. The limits of detection for all BA was $1 \mu \mathrm{g} / \mathrm{g}$. Chromatograms of faecal BA from one dog (id 7), are shown in Additional file 4.

\section{Statistical methods}

Data were tested for normality using the Shapiro-Wilk normality. Non-parametric Wilcoxon signed-rank test was used to calculate statistical differences between the various $\mathrm{BA}$ between the diet periods (CD1 vs $\mathrm{HMB}$ and $\mathrm{CD} 2$ vs $\mathrm{HMB}$ ) without correction for multiple comparison. The software Graph Pad, PRISM v.7 (CA, USA) was used. A two-dimensional Principal component analysis (PCA) plot was generated using PRIMER7 [36]. A P value below 0.05 was considered statistically significant.

\section{Results}

The secondary BA, DCA were significantly higher in the HMB samples compared with the levels in both CD1 and CD2 samples $(P=0.05$ and 0.04 , respectively). Higher quantities of UDCA were detected in the HMB samples compared with that of $C D 2$ samples $(P=0.02)$, but this was not significant when compared to $\mathrm{CD} 1$ samples ( $P>0.1$, Fig. 1). Although the median values for the primary BA, CA and CDCA were higher in HMB samples, the differences were not statistically significant $(\mathrm{P}>0.1$, Fig. 1). However, the levels of taurine-conjugated BA were significantly higher in the HMB samples compared with the $\mathrm{CD} 2$ samples $(\mathrm{P}=0.02)$, but not compared with $\mathrm{CD} 1$ samples $(\mathrm{P}>0.5)$. Concentrations of glycine-conjugated BA were measured, but were below quantification limit in all dogs (Table 2).

As evaluated by a PCA plot, the majority of $\mathrm{HMB}$ samples are displayed along the first axis (PC1) and the 


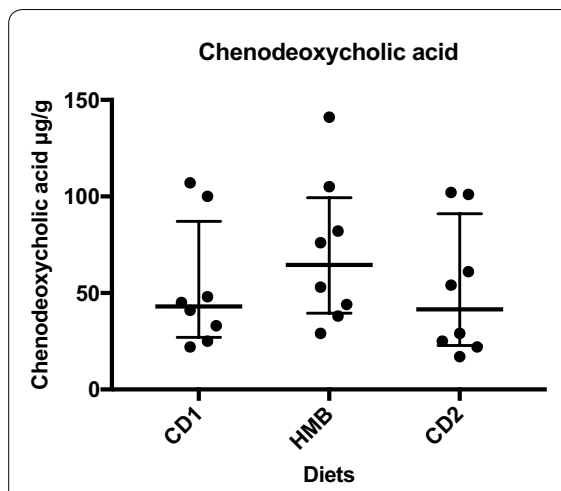

Deoxycholic acid

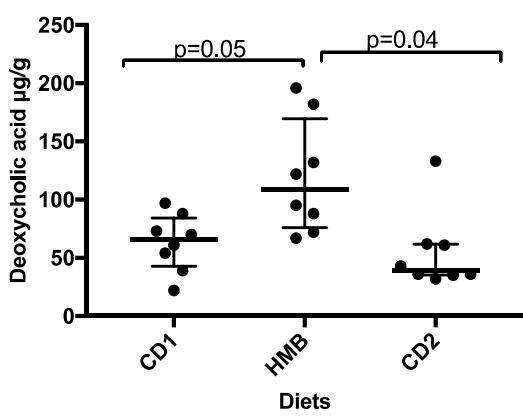

Cholic acid

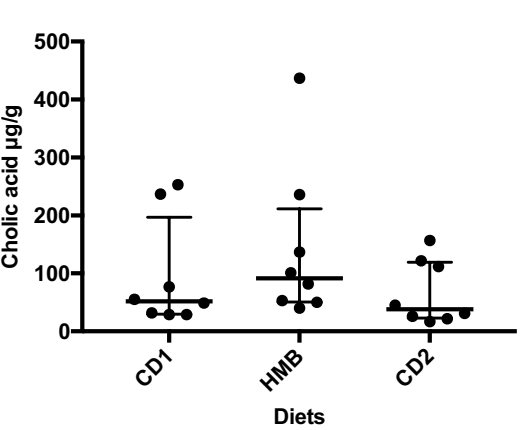

Lithocholic acid

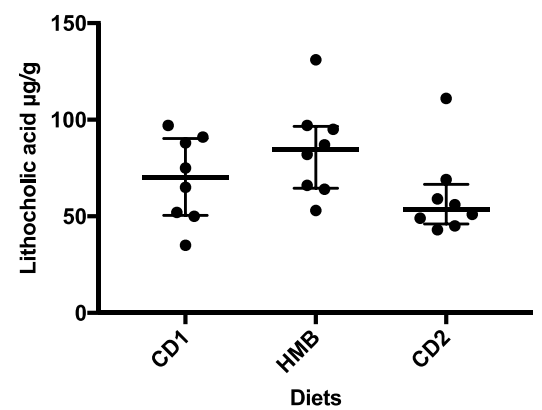

Urseodeoxycholic acid

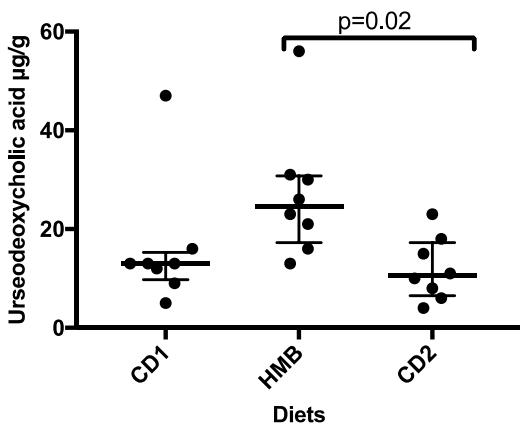

Taurine-conj. BA

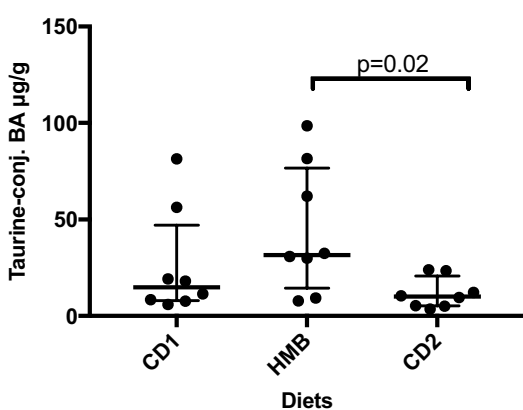

Fig. 1 Median concentrations with interquartile ranges of bile acids (BA) ( $\mu \mathrm{g} / \mathrm{g}$ faeces) in samples of eight dogs fed commercial dry food at the start and end of the study (CD1 and CD2) and high minced beef (HMB). Significant differences of faecal BA in diet periods CD1 vs HMB and CD2 vs HMB are indicated (Wilcoxon signed-rank test without correction for multiple comparison). CD1 Commercial dry food given the first 2 weeks of the study, CD2 commercial dry food given the last 2 weeks of the study, HMB high minced beef, CA cholic acid, CDCA chenodeoxycholic acid, DCA deoxycholic acid, LCA litocholic, UDCA ursodeoxycholic acid, Taurine-conj. BA (taurine-conjugated CA, CDCA, DCA, and LCA)

vectors (bile acids), particularly LCA, DCA and UDCA, are directed towards the HMB samples (Fig. 2).

The variability in breed, age and body size between both genders of dogs made it impossible to perform any statistical testing for any possible impact of these factors on the faecal BA composition.

\section{Discussion}

A diet shift from commercial dry food (CD) to high minced beef $(\mathrm{HMB})$ and vice versa, during a 7-week dietary intervention study influenced faecal BA profiles in healthy client-owned dogs. Specifically, the secondary BA, DCA and UDCA increased in the HMB samples compared with the CD1 and/or CD2 samples, likely due to the presence of colonic bacteria with 7 alpha-dehydroxylating capabilities that transform primary BA to secondary BA. It is known that members within Clostridium and Eubacterium have this capability [13, 37]. We have previously reported, using the same study population, significantly higher relative abundances of an OTU in the family Clostridiaceae in the HMB samples [32]. This bacterial taxa was classified within a BLAST search to be Clostridia hiranonis with $97 \%$ identity. Interestingly, this species is capable of converting CA and CDCA into DCA and LCA, respectively [38]. Thus, the increased presence of this taxa may explain the higher faecal quantity of DCA in dogs fed HMB. The concomitant rise in the quantity of UDCA, rather than LCA, may indicate the possibility that increased bacterial transformation of CDCA to UDCA [14] is more likely to occur than bacterial transformation of CDCA to LCA in dogs. Moreover, the bacterial 7 beta-dehydroxylation of UDCA yield LCA [13, 39], but the low quantity of LCA may suggest that this process is not dominant in the intestine of dogs. However, since we used a semi-quantitative approach, these results needs to be validated in studies where the exact faecal quantities of BA are measured.

The apparent lack of glycine-conjugated BA in the faeces, yet detectable levels of taurine-conjugated BA, confirm that dogs primarily conjugate their bile acids with taurine rather than glycine [40-42]. Furthermore, the significantly higher taurine-conjugated BA levels measured in the faeces collected during the HMB period compared to the CD2 period suggest that the high lipid levels of the HMB diet can induce greater primary BA secretion. However, observed levels of primary BA, CA and 
Table 2 Concentrations of faecal bile acids $(\mu \mathrm{g} / \mathrm{g})$

\begin{tabular}{|c|c|c|c|c|c|c|c|c|c|c|c|c|}
\hline$\overline{D o g \_i d{ }^{a}}$ & Diet & $C A$ & CDCA & DCA & LCA & UDCA & G-DCA & G-LCA & T-CA & T-CDCA & T-DCA & T-LCA \\
\hline \multirow[t]{3}{*}{1} & CD1 & 32 & 41 & 54 & 52 & 13 & 1 & 1 & 3 & 1 & 1 & 0 \\
\hline & $\mathrm{HMB}$ & 40 & 53 & 67 & 53 & 21 & 0 & 2 & 5 & 1 & 1 & 0 \\
\hline & $\mathrm{CD} 2$ & 112 & 61 & 36 & 43 & 8 & 4 & 2 & 2 & 1 & 1 & 0 \\
\hline \multirow[t]{3}{*}{3} & CD1 & 55 & 45 & 73 & 65 & 16 & 2 & 1 & 5 & 2 & 2 & 0 \\
\hline & $\mathrm{HMB}$ & 437 & 105 & 182 & 95 & 56 & 4 & 1 & 28 & 1 & 52 & 1 \\
\hline & $\mathrm{CD} 2$ & 122 & 102 & 62 & 59 & 23 & 0 & 2 & 4 & 1 & 1 & 0 \\
\hline \multirow[t]{3}{*}{4} & CD1 & 49 & 48 & 97 & 97 & 13 & 5 & 1 & 19 & 7 & 41 & 14 \\
\hline & $\mathrm{HMB}$ & 50 & 29 & 72 & 66 & 13 & 0 & 1 & 31 & 4 & 22 & 5 \\
\hline & $\mathrm{CD} 2$ & 26 & 25 & 43 & 56 & 11 & 0 & 1 & 11 & 2 & 7 & 4 \\
\hline \multirow[t]{3}{*}{5} & CD1 & 29 & 25 & 61 & 75 & 12 & 2 & 1 & 5 & 2 & 8 & 3 \\
\hline & $\mathrm{HMB}$ & 53 & 38 & 95 & 82 & 26 & 4 & 2 & 7 & 1 & 17 & 5 \\
\hline & CD2 & 22 & 22 & 36 & 49 & 10 & 2 & 1 & 1 & 0 & 2 & 1 \\
\hline \multirow[t]{3}{*}{6} & CD1 & 29 & 22 & 39 & 50 & 9 & 2 & 1 & 2 & 1 & 5 & 3 \\
\hline & $\mathrm{HMB}$ & 137 & 76 & 132 & 97 & 30 & 7 & 3 & 10 & 1 & 16 & 4 \\
\hline & $\mathrm{CD} 2$ & 17 & 17 & 32 & 45 & 6 & 6 & 2 & 2 & 1 & 5 & 2 \\
\hline \multirow[t]{3}{*}{7} & CD1 & 77 & 33 & 22 & 35 & 5 & 8 & 1 & 2 & 1 & 3 & 2 \\
\hline & $\mathrm{HMB}$ & 236 & 82 & 196 & 131 & 31 & 10 & 3 & 21 & 3 & 66 & 9 \\
\hline & CD2 & 31 & 29 & 35 & 51 & 4 & 5 & 2 & 3 & 1 & 4 & 2 \\
\hline \multirow[t]{3}{*}{10} & CD1 & 253 & 107 & 88 & 88 & 13 & 8 & 2 & 8 & 2 & 7 & 2 \\
\hline & $\mathrm{HMB}$ & 82 & 44 & 88 & 64 & 16 & 11 & 3 & 2 & 1 & 5 & 1 \\
\hline & $\mathrm{CD} 2$ & 157 & 101 & 133 & 111 & 18 & 18 & 3 & 7 & 2 & 11 & 4 \\
\hline \multirow[t]{3}{*}{11} & CD1 & 237 & 100 & 70 & 91 & 47 & 0 & 1 & 29 & 7 & 15 & 6 \\
\hline & $\mathrm{HMB}$ & 101 & 141 & 122 & 87 & 23 & 3 & 2 & 11 & 1 & 17 & 3 \\
\hline & $\mathrm{CD} 2$ & 45 & 54 & 61 & 69 & 15 & 5 & 2 & 3 & 1 & 6 & 2 \\
\hline
\end{tabular}

The concentrations were determined semiquantitatively

CA cholic acid, CDCA chenodeoxycholic acid, DCA deoxycholic acid, LCA litocholic, UDCA ursodeoxycholic acid, glycine-conjugated DCA (G-DCA) and LCA (G-LCA), taurine-conjugated CA (T-CA), CDCA (T-CDCA), DCA (T-DCA), and LCA (T-LCA))

a Detailed demographics of these dogs are given in Table 1

CDCA were variable between dogs and not significantly increased in response to the HMB diet. The variable response between dogs in this study may be explained by differing BA metabolism, intestinal peristalsis, intestinal $\mathrm{pH}$ and/or gastrointestinal absorption of $\mathrm{BA}$, as well as differences in the intestinal microbiota composition, which may result in different levels of secondary bile acid in response to diet in these individuals $[1,43]$.

The hydrophobicity of the BA influences their cytotoxic potential, ranking UDCA as the most hydrophilic and LCA as the most hydrophobic (BA hydrophobicity scale: $\mathrm{UDCA}<\mathrm{CA}<\mathrm{CDCA}<\mathrm{DCA}<\mathrm{LCA}$ ) [44]. DCA has been shown to induce oxidative damage of DNA in vitro, which may result in abnormal cell proliferation of mutagenic, apoptosis-resistant cells [17, 45-47]. In contrast to the possible cytotoxic effects of DCA and LCA on colonic cells, UDCA is believed to have chemoprotective potential $[19,48]$. A previous study of ten laboratory dogs described that oral treatment with UDCA resulted in lower ratio of secondary to primary BA [10]. Interestingly, the quantity of faecal UDCA in humans appear to be low in general [49], in contrast to the levels in dogs observed in this study. Whether dogs generally are adapted to having an intestinal microbiota that transform higher quantities of primary BA to UDCA compared to humans, also in response to a high-fat intake, merits further investigations.

In contrast to dietary fat, plant-fibre is thought to protect against colorectal cancer development in humans. Dietary fibres are fermented to short chain fatty acids (SCFA), which purportedly have anti-inflammatory and anti-carcinogenic properties [50]. One mode of action suggested is that the production of SCFA by bacterial fermentation of non-digestible carbohydrates reduces luminal $\mathrm{pH}$ and bacterial 7 alpha-dehydroxylase activity, and hence conversion of primary to the secondary BA, DCA and LCA is inhibited [51]. Fibres also bind to BA and thus facilitate their excretion [52]. Moreover, antioxidants in plants, such as beta-carotene and alpha-tocopherol may inhibit the detrimental effects of DCA on colonic cells [47]. In dogs, animal-fibres, such as collagen, has been suggested to have the same properties as plant-fibre [53], 


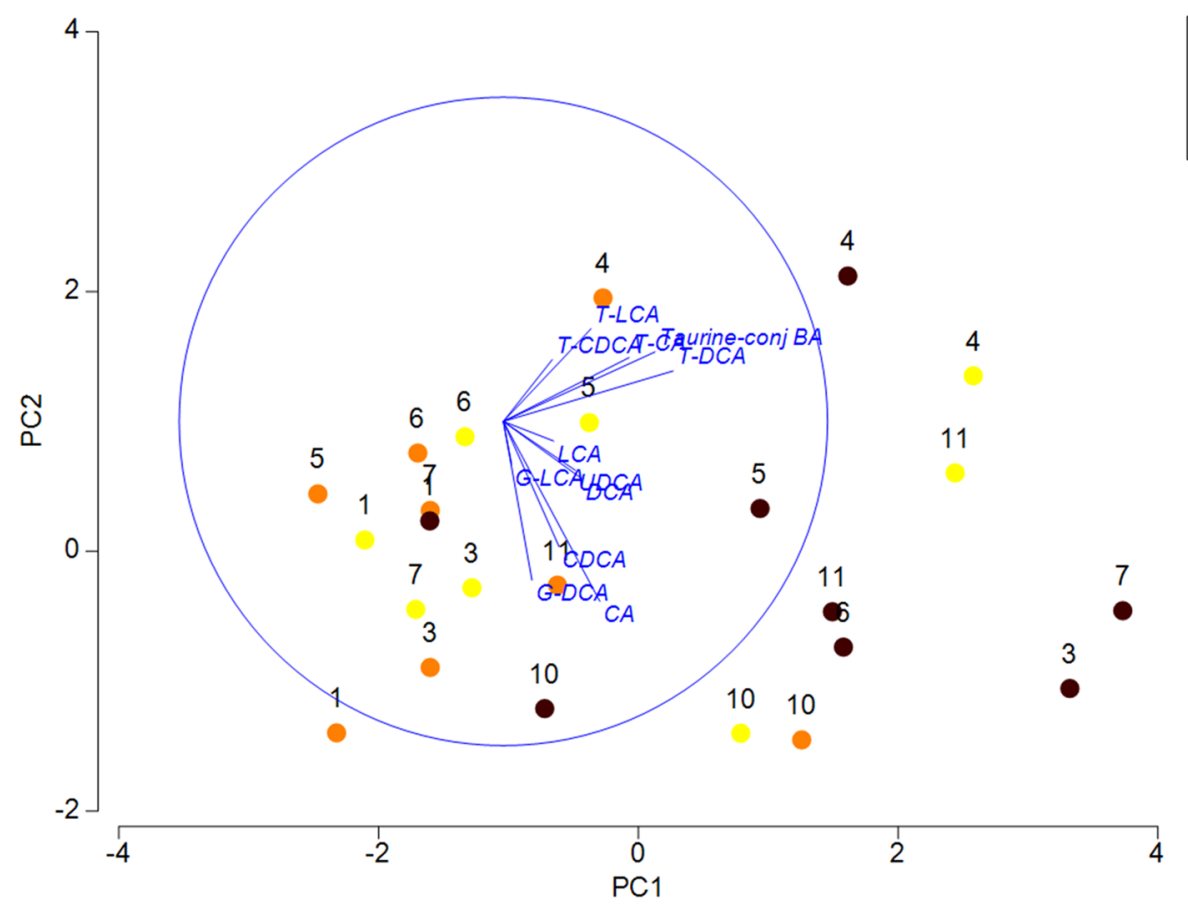

Fig. 2 A Principal component analysis (PCA) plot showing the relationship between samples. The data are displayed across the two main principal components (PC1 and PC2). Each point represents one sample and each colour represents diet period. Closer clustering between points indicate higher relative commonality with respect to bile acid composition in those samples. Concomitantly, larger distances between points indicate lower relative commonality of bile acid composition in those samples. The first axis, $\mathrm{PC} 1$ accounted for $55 \%$ of the variability and PC2 accounted for $20 \%$ of the variability. The directions of the vectors (blue lines) corresponding to BA, particularly LCA, UDCA and DCA are directed towards the HMB samples. CD1 Commercial dry food given the first 2 weeks of the study, yellow points; CD2 commercial dry food given the last 2 weeks of the study, orange points, HMB high minced beef, black points, CA cholic acid, CDCA chenodeoxycholic acid, DCA deoxycholic acid, LCA litocholic, UDCA ursodeoxycholic acid, Taurine-conj. BA (taurine-conjugated CA, CDCA, DCA, and LCA)

and thereby limit any potential toxic effects from secondary BA.

In humans, a diet with high content of protein and fat and low content of fibre, is associated with a higher risk of colorectal cancer $[8,54,55]$. Moreover, elevated serum and faecal levels of DCA have been observed in humans with colorectal adenoma and carcinoma compared with healthy controls $[56,57]$. Dogs are fed various diets, which also include more animal-based diets preferred by some pet owners $[58,59]$. Yet dogs rarely develop colorectal cancer [21, 60]. Given dogs' carnivorous origins, it may not be surprising to find metabolic differences between humans and dogs that can explain differences in the risks of developing chronic intestinal, associated digestive organ and systemic diseases. For instance, dogs' lipoprotein transportation of fat differs from that of humans [61], which may be the reason why atherosclerosis is not a major issue in dogs. Future studies should evaluate the faecal levels of BA, and particularly DCA and UDCA in dogs with colorectal cancer, non-tumour related colonic diseases, as well as healthy controls to gain an understanding of BA involvement in intestinal health in dogs.

The main limitation of this study was the small and heterogeneous sample size. Factors such as age, breed, body size/weight, gender, as well as previously fed diets may have influenced the faecal bile acid composition in our dogs. Previous studies have found that these aforementioned factors may influence the intestinal microbiota composition [62-65]. Whether the metabolites produced by the microbiota, including bile acids, also are influenced by these factors needs to be determined in future, adequately powered studies. Moreover, the influence of the individual dietary components, such as fat, starch, proteins, micronutrients, fibre, collagen etc., on the outcome was not tested. Although the discussion primarily focused on the influence of dietary fat, the presence and/or absence of other diet components most likely also influenced the faecal bile acid composition. 


\section{Conclusions}

A diet shift from commercial dry food to one of high beef content and vice versa, resulted in changes in the faecal BA profiles of healthy client-owned dogs. A high-fat/lowfibre diet in humans results in accumulation of secondary BA in the colon, particularly DCA, which has cytotoxic effects on colonic cells. Interestingly, our results in dogs revealed that the increase in DCA was accompanied by an increase in UDCA, the latter believed to have a chemoprotective mode of action. Since dogs have evolved from carnivorous wolves, and therefore presumed tolerant of high protein, high fat diets, they may have a different metabolism of BA, or have protective mechanisms against potential harmful effects induced by secondary $\mathrm{BA}$, in order to maintain colonic health. Further studies are needed to more specifically evaluate the role of BA in colonic diseases of dogs.

\section{Additional files}

Additional file 1. Ingredients and nutrient composition of the rations during the seven-week dietary intervention study (a), and main ingredients in CD (b).

Additional file 2. A detailed overview of the BA characterized by LC-MS/ MS.

Additional file 3. The monitored ion transitions and compound specific parameters (a). Common MS/MS-parameters for all ion transitions (b).

Additional file 4. Chromatograms of faecal LCA (a), CA (b), DCA (c), CDCA (d) and UDCA (e) from one dog (id 7) fed commercial dry food the first two weeks of the study (CD1) and the last two weeks of the study (CD2) and high minced beef $(\mathrm{HMB})$

\begin{abstract}
Abbreviations
BA: bile acids; CA: cholic acid; CD: commercial dry food; CDCA: chenodeoxycholic acid; DCA: deoxycholic acid; DM: dry matter; HMB: high minced beef; LC-MS/MS: liquid chromatography-tandem mass spectrometry; LMB: low minced beef; MB: minced beef; MMB: moderate minced beef; MPB: mobile phase B; NFE: nitrogen-free extract; OTU: operational taxonomic unit; PCA: principal component analysis; SCFA: short chain fatty acid; UDCA: ursodeoxycholic acid.
\end{abstract}

\section{Authors' contributions}

$\mathrm{KH}, \mathrm{ES}$ and $\mathrm{LM}$ designed the study. $\mathrm{KH}$ performed sample collection. AMB calculated the rations for the different diet periods. KH performed laboratory work. HTR conducted the LC-MS/MS-analysis. KH performed the statistical analysis. KH wrote the manuscript, with contributions from all authors during manuscript preparation. All authors read and approved the final manuscript.

\section{Author details}

${ }^{1}$ Department of Companion Animal Clinical Sciences, Faculty of Veterinary Medicine, Norwegian University of Life Sciences (NMBU), Oslo, Norway. ${ }^{2}$ Matriks AS, Forskningsparken, Gaustadallèen 21, 0349 Oslo, Norway. ${ }^{3}$ Department of Basic Sciences and Aquatic Medicine, Faculty of Veterinary Medicine, Norwegian University of Life Sciences (NBMU), Oslo, Norway.

\section{Acknowledgements}

The authors thank Christina Steppeler for her excellent help with the preparation of samples used for the analysis of BAs and Professor Eystein Skjerve for valuable comments during the statistical analysis. We would also like to express our gratitude to the dog-owners and dogs participating in this study.

\section{Competing interests}

The authors declare that they have no competing interests.

\section{Availability of data and materials}

The datasets used and/or analysed during the current study are available from the corresponding author on reasonable request.

\section{Consent to publish}

Not applicable.

\section{Ethics approval and consent to participate}

The study protocol was reviewed and approved according to the guidelines of the ethics committee at the Faculty of Veterinary Medicine and Biosciences, Norwegian University of Life Sciences (NMBU) (Approval Number: 14/04723-

23). All dog-owners gave a written informed consent before participation and were informed that they could leave the study at any time.

\section{Funding}

The Felleskjøpet and the Astri and Birger Torsted Foundation provided financial support.

\section{Publisher's Note}

Springer Nature remains neutral with regard to jurisdictional claims in published maps and institutional affiliations.

Received: 10 November 2017 Accepted: 3 May 2018

Published online: 11 May 2018

\section{References}

1. Hofmann AF, Hagey LR, Krasowski MD. Bile salts of vertebrates: structural variation and possible evolutionary significance. J Lipid Res. 2010;512:226-46

2. Fiorucci S, Distrutti E. Bile acid-activated receptors, intestinal microbiota, and the treatment of metabolic disorders. Trends Mol Med. 2015;2111:702-14.

3. Makishima M, Okamoto AY, Repa JJ, Tu H, Learned RM, Luk A, et al. Identification of a nuclear receptor for bile acids. Science. 1999;2845418:1362-5.

4. Nguyen A, Bouscarel B. Bile acids and signal transduction: role in glucose homeostasis. Cell Signal. 2008;2012:2180-97.

5. Fiorucci S, Cipriani S, Mencarelli A, Renga B, Distrutti E, Baldelli F. Counterregulatory role of bile acid activated receptors in immunity and inflammation. Curr Mol Med. 2010;106:579-95.

6. Bernstein H, Bernstein C, Payne CM, Dvorakova K, Garewal H. Bile acids as carcinogens in human gastrointestinal cancers. Mutat Res. 2005:5891:47-65.

7. Bernstein $\mathrm{C}$, Holubec $\mathrm{H}$, Bhattacharyya AK, Nguyen H, Payne CM, Zaitlin B, et al. Carcinogenicity of deoxycholate, a secondary bile acid. Arch Toxicol. 2011;858:863-71.

8. O'Keefe SJ, Li JV, Lahti L, Ou J, Carbonero F, Mohammed K, et al. Fat, fibre and cancer risk in African Americans and rural Africans. Nat Commun. 2015;6:6342.

9. Kim I, Ahn SH, Inagaki T, Choi M, Ito S, Guo GL, et al. Differential regulation of bile acid homeostasis by the farnesoid $X$ receptor in liver and intestine. J Lipid Res. 2007:4812:2664-72.

10. Imamura M, Nakajima H, Takahashi H, Yamauchi H, Seo G. Bile acid metabolism, bacterial bowel flora and intestinal function following ileal pouchanal anastomosis in dogs, with reference to the influence of administration of ursodeoxycholic acid. Tohoku J Exp Med. 2000;1902:103-17.

11. Zhang J, He K, Cai L, Chen YC, Yang Y, Shi Q, et al. Inhibition of bile salt transport by drugs associated with liver injury in primary hepatocytes from human, monkey, dog, rat, and mouse. Chem Biol Interact. 2016;255:45-54.

12. Borgstrom B, Lundh $G$, Hofmann A. The site of absorption of conjugated bile salts in man. Gastroenterology. 1968;544(Suppl):781-3.

13. Ridlon JM, Kang DJ, Hylemon PB. Bile salt biotransformations by human intestinal bacteria. J Lipid Res. 2006;472:241-59. 
14. Hirano S, Masuda N, Oda H. In vitro transformation of chenodeoxycholic acid and ursodeoxycholic acid by human intestinal flora, with particular reference to the mutual conversion between the two bile acids. J Lipid Res. 1981;225:735-43

15. Axelsson E, Ratnakumar A, Arendt ML, Maqbool K, Webster MT, Perloski M, et al. The genomic signature of dog domestication reveals adaptation to a starch-rich diet. Nature. 2013;4957441:360-4.

16. Dressman JB. Comparison of canine and human gastrointestinal physiology. Pharm Res. 1986;33:123-31.

17. Bernstein C, Bernstein H, Garewal H, Dinning P, Jabi R, Sampliner RE, et al. A bile acid-induced apoptosis assay for colon cancer risk and associated quality control studies. Cancer Res. 1999;5910:2353-7.

18. Cao H, Luo S, Xu M, Zhang Y, Song S, Wang S, et al. The secondary bile acid, deoxycholate accelerates intestinal adenoma-adenocarcinoma sequence in $\mathrm{Apc}(\mathrm{min} /+)$ mice through enhancing Wnt signaling. Fam Cancer. 2014;134:563-71.

19. Akare S, Jean-Louis S, Chen W, Wood DJ, Powell AA, Martinez JD. Ursodeoxycholic acid modulates histone acetylation and induces differentiation and senescence. Int J Cancer. 2006;1 1912:2958-69.

20. Im E, Martinez JD. Ursodeoxycholic acid (UDCA) can inhibit deoxycholic acid (DCA)-induced apoptosis via modulation of EGFR/Raf-1/ERK signaling in human colon cancer cells. J Nutr. 2004;1342:483-6.

21. Schäffer E. Incidence and types of canine rectal carcinomas. J Small Anim Pract. 1968;9:491-6.

22. Valerius KD, Powers BE, McPherron MA, Hutchison JM, Mann FA, Withrow SJ. Adenomatous polyps and carcinoma in situ of the canine colon and rectum: 34 cases (1982-1994). J Am Anim Hosp Assoc. 1997;33:156-60.

23. Lingeman CH, Garner FM. Comparative study of intestinal adenocarcinomas of animals and man. J Natl Cancer Inst. 1972;482:325-46.

24. Tang J, Le S, Sun L, Yan X, Zhang M, Macleod J, et al. Copy number abnormalities in sporadic canine colorectal cancers. Genome Res. 2010;203:341-50.

25. Tang J, Li Y, Lyon K, Camps J, Dalton S, Ried T, et al. Cancer driver-passenger distinction via sporadic human and dog cancer comparison: a proofof-principle study with colorectal cancer. Oncogene. 2014;337:814-22.

26. Youmans L, Taylor C, Shin E, Harrell A, Ellis AE, Seguin B, et al. Frequent alteration of the tumor suppressor gene APC in sporadic canine colorectal tumors. PLoS ONE. 2012. https://doi.org/10.1371/journal.pone.00508 13.

27. Gerritzen-Bruning MJ, van den Ingh TS, Rothuizen J. Diagnostic value of fasting plasma ammonia and bile acid concentrations in the identification of portosystemic shunting in dogs. J Vet Intern Med. 2006;201:13-9.

28. Blake AB, Guard BC, Honneffer JB, Kumro FG, Kennedy OC, Lidbury JA, et al. Dogs with exocrine pancreatic insufficiency have dysbiosis and abnormal fecal lactate and bile acid concentrations. American College of Veterinary Internal Medicine (ACVIM) abstracts; Maryland, USA, 2017. J Vet Intern Med. 2017;31:1286.

29. Guard BC, Alexander C, Honneffer JB, Lidbury JA, Steiner JM, Swanson KS, et al. Effect of the bile acid sequestrand cholestyramine on fecal bile acid concentrations in healthy dogs. American College of Veterinary Internal Medicine (ACVIM) abstracts; Maryland, USA, 2017. J Vet Intern Med. 2017;31:1280.

30. Guard BC, Jonika MM, Honneffer JB, Lidbury JA, Steiner JM, Suchodolski JS. Development and analytical validation of an assay for the quantification of canine fecal bile acids. American College of Veterinary Internal Medicine (ACVIM) abstracts; Maryland, USA, 2017. J Vet Intern Med. 2017;31:1289.

31. Moxham G. Waltham feces scoring system- A tool for veterinarians and pet owners. How does your pet rate? Waltham ${ }^{\circledR}$ Focus. 2001;112:24-45.

32. Herstad KMV, Gajardo K, Bakke AM, Moe L, Ludvigsen J, Rudi K, et al. A diet change from dry food to beef induces reversible changes on the faecal microbiota in healthy, adult client-owned dogs. BMC Vet Res. 2017;131:147.

33. Thes M, Koeber N, Fritz J, Wendel F, Dillitzer N, Dobenecker B, et al. Metabolizable energy intake of client-owned adult dogs. J Anim Physiol Anim Nutr (Berl). 2016;1005:813-9.

34. Hartviksen M, Bakke AM, Vecino JG, Ringo E, Krogdahl A. Evaluation of the effect of commercially available plant and animal protein sources in diets for Atlantic salmon (Salmo salar L.): digestive and metabolic investigations. Fish Physiol Biochem. 2014;40:1621-37.
35. Hagio M, Matsumoto M, Fukushima M, Hara H, Ishizuka S. Improved analysis of bile acids in tissues and intestinal contents of rats using LC/ ESI-MS. J Lipid Res. 2009;501:173-80.

36. Clarke KR, Gorley RN. PRIMER v7: user manual/tutorial. Plymouth: PRIMERE; 2015. p. 296

37. Doerner KC, Takamine F, LaVoie CP, Mallonee DH, Hylemon PB. Assessment of fecal bacteria with bile acid 7 alpha-dehydroxylating activity for the presence of bai-like genes. Appl Environ Microbiol. 1997;633:1185-8.

38. Kitahara M, Takamine F, Imamura T, Benno Y. Clostridium hiranonis sp. nov, a human intestinal bacterium with bile acid 7alpha-dehydroxylating activity. Int J Syst Evol Microbiol. 2001;51:39-44.

39. Ridlon JM, Harris SC, Bhowmik S, Kang DJ, Hylemon PB. Consequences of bile salt biotransformations by intestinal bacteria. Gut Microbes. 2016;71:22-39.

40. Nakayama F. Composition of gallstone and bile: species difference. J Lab Clin Med. 1969;734:623-30.

41. Wildgrube HJ, Stockhausen H, Petri J, Fussel U, Lauer H. Naturally occurring conjugated bile acids, measured by high-performance liquid chromatography, in human, dog, and rabbit bile. J Chromatogr. 1986;353:207-13.

42. Washizu T, Ikenaga H, Washizu M, Ishida T, Tomoda I, Kaneko JJ. Bile acid composition of dog and cat gall-bladder bile. Nihon Juigaku Zasshi. 1990;522:423-5.

43. Jones BV, Begley M, Hill C, Gahan CG, Marchesi JR. Functional and comparative metagenomic analysis of bile salt hydrolase activity in the human gut microbiome. Proc Natl Acad Sci USA. 2008;10536:13580-5.

44. Hofmann AF. Bile acids: the good, the bad, and the ugly. News Physiol Sci. 1999;14:24-9.

45. Booth LA, Gilmore IT, Bilton RF. Secondary bile acid induced DNA damage in HT29 cells: are free radicals involved? Free Radic Res. 1997;262:135-44.

46. Glinghammar B, Inoue H, Rafter JJ. Deoxycholic acid causes DNA damage in colonic cells with subsequent induction of caspases, COX-2 promoter activity and the transcription factors NF-kB and AP-1. Carcinogenesis. 2002;235:839-45

47. Rosignoli P, Fabiani R, De Bartolomeo A, Fuccelli R, Pelli MA, Morozzi G. Genotoxic effect of bile acids on human normal and tumour colon cells and protection by dietary antioxidants and butyrate. Eur J Nutr. 2008:476:301-9.

48. Alberts DS, Martinez ME, Hess LM, Einspahr JG, Green SB, Bhattacharyya AK, et al. Phase III trial of ursodeoxycholic acid to prevent colorectal adenoma recurrence. J Natl Cancer Inst. 2005;9711:846-53.

49. Kakiyama G, Muto A, Takei H, Nittono H, Murai T, Kurosawa T, et al. A simple and accurate HPLC method for fecal bile acid profile in healthy and cirrhotic subjects: validation by GC-MS and LC-MS. J Lipid Res. 2014;555:978-90.

50. Macfarlane GT, Macfarlane S. Bacteria, colonic fermentation, and gastrointestinal health. J AOAC Int. 2012;951:50-60.

51. Bingham SA. Diet and colorectal cancer prevention. Biochem Soc Trans. 2000;282:12-6.

52. Kritchevsky D. Influence of dietary fiber on bile acid metabolism. Lipids. 1978;1312:982-5.

53. Depauw S, Hesta M, Whitehouse-Tedd K, Vanhaecke L, Verbrugghe A, Janssens GP. Animal fibre: the forgotten nutrient in strict carnivores? First insights in the cheetah. J Anim Physiol Anim Nutr (Berl). 2011;971:146-54.

54. Cross AJ, Ferrucci LM, Risch A, Graubard BI, Ward MH, Park Y, et al. A large prospective study of meat consumption and colorectal cancer risk: an investigation of potential mechanisms underlying this association. Cancer Res. 2010;706:2406-14.

55. Russell WR, Gratz SW, Duncan SH, Holtrop G, Ince J, Scobbie L, et al. High-protein, reduced-carbohydrate weight-loss diets promote metabolite profiles likely to be detrimental to colonic health. Am J Clin Nutr. 2011;935:1062-72.

56. Reddy BS, Wynder EL. Metabolic epidemiology of colon cancer. Fecal bile acids and neutral sterols in colon cancer patients and patients with adenomatous polyps. Cancer. 1977;396:2533-9.

57. Bayerdorffer E, Mannes GA, Ochsenkuhn T, Dirschedl P, Wiebecke B, Paumgartner $G$. Unconjugated secondary bile acids in the serum of patients with colorectal adenomas. Gut. 1995;362:268-73.

58. Freeman LM, Michel KE. Evaluation of raw food diets for dogs. J Am Vet Med Assoc. 2001;2185:705-9. 
59. Laflamme DP, Abood SK, Fascetti AJ, Fleeman LM, Freeman LM, Michel $K E$, et al. Pet feeding practices of dog and cat owners in the United States and Australia. J Am Vet Med Assoc. 2008;2325:687-94.

60. Van der Gaag I. The histological appearance of large intestinal biopsies in dogs with clinical signs of large bowel disease. Can J Vet Res. 1988;521:75-82.

61. Bauer JE. Lipoprotein-mediated transport of dietary and synthesized lipids and lipid abnormalities of dogs and cats. J Am Vet Med Assoc. 2004;2245:668-75.

62. Benno Y, Nakao H, Uchida K, Mitsuoka T. Impact of the advances in age on the gastrointestinal microflora of beagle dogs. J Vet Med Sci. 1992;544:703-6.
63. Kim J, An JU, Kim W, Lee S, Cho S. Differences in the gut microbiota of dogs (Canis lupus familiaris) fed a natural diet or a commercial feed revealed by the Illumina MiSeq platform. Gut Pathog. 2017;9:68.

64. Li Q, Lauber CL, Czarnecki-Maulden G, Pan Y, Hannah SS. Effects of the dietary protein and carbohydrate ratio on gut microbiomes in dogs of different body conditions. MBio. 2017;8(1):e01703-16. https://doi. org/10.1128/mBio.01703-16.

65. Simpson JM, Martineau B, Jones WE, Ballam JM, Mackie RI. Characterization of fecal bacterial populations in canines: effects of age, breed and dietary fiber. Microb Ecol. 2002;442:186-97.
Ready to submit your research? Choose BMC and benefit from:

- fast, convenient online submission

- thorough peer review by experienced researchers in your field

- rapid publication on acceptance

- support for research data, including large and complex data types

- gold Open Access which fosters wider collaboration and increased citations

- maximum visibility for your research: over $100 \mathrm{M}$ website views per year

At BMC, research is always in progress.

Learn more biomedcentral.com/submissions 